\title{
The Study of Human Resource Withdrawal Based on the Internal Control
}

\author{
Chen $\mathrm{CHEN}^{1, a}$, Ji-Xue YUAN ${ }^{1, \mathrm{~b},{ }^{*}}$ \\ ${ }^{1}$ No.3501 Daxue Road, Changqing District, Jinan, P.R.China 250353 \\ alittlechenschen@163.com, byjxjcd@163.com \\ ${ }^{*}$ Corresponding author
}

Keywords: Human resources, Human resources withdrawal (HRW), Internal control.

\begin{abstract}
This study focuses on comprehension of the Human Resource Withdrawal (HRW) behaviors of the employees during the organizations' modern Human Resources Management (HRM) process, especially in general trend of internal control. Firstly, we give a self-made definition and classification of the HRW creativity, and then we analyze the causes according to the specialty classification which including the managers, professional technical personnel and operational employees. Moreover, we try to draw a diagram to match the most suitable ways between different types' employees and HRW ways which both been mentioned former. Finally, we point out the keys about what should be noted in a sound human resources withdrawal mechanism.
\end{abstract}

\section{Introduction}

As the last section, Human Resources Withdrawal (HRW) throughout all steps and plays a critical role in HRM. In 2010, the five ministries which headed by the Ministry of Finance in China promulgate the No.3 of the Application Guidelines for Enterprise Internal Control -Human Resources, which put the human resources as a single project, and take it into the scope of internal control. The "Guidelines" also point out the organization should focus on the problems that might occur during the modern HRM process which include the recruit, development, use and withdrawal. In addition, The "Guidelines" make it clear that the illegitimate human resources withdrawal mechanism may result in disrepute or law litigation, which is one of the main risks in the HRM process. Thus, improving the system of HRW is both benefit the HRM and the internal control environment.

\section{Definition and Classification}

To date, no clear, authoritative definition of HRW has been made by western and domestic scholars [1]. After summarizing the research results, we want to give a thoughtful and balanced definition of what a real human resources withdrawal behavior (HRW) looks like. Thus, this paper believes that the HRW is a process that the employees definitely leave or deemed leave the organization through a mass of the mutual accommodations and adaptation between employees and employers. In particular, the "definitely leave" means the employment relationship is formal over, and the "deemed leave" means the employment relationship is still existence, the employees still work in the original organization as the nominal or non-nominal forms, whereas the original work actually has been severely reduced.

A considerable part of the current literatures have defined the HRW in scope. For example, it can be divided into the intra-organizational withdraw and extra-organizational withdraw according to the membership credentials, it can be divided into the natural withdraw and unnatural withdraw according to the objective condition, and it can be divided into the initiative withdraw and passive withdraw according to employees' intent [2-4]. Combined with all researches, we classified the HRW into three forms. They are named individual causes withdraw, legal causes withdraw and the organizational needs withdraw based on the motive. In particular, the concrete forms of individual causes withdraw include the resign, voluntary turnover, duty dereliction resignation and active incumbency unemployment; the concrete forms of legal causes withdraw include the contract expire turnover, retirement, illness and died; and the concrete forms of the organizational needs withdraw include the rigid and flexible 
withdraw forms. Particularly, the former include the staff reduction, dismissal, and lay off the last system, and the later include the rebuilding venture, internal venturing, internal labor market, suspension, training, early retirement, flow in the post, passive incumbency unemployment and human resources rent. In this paper, we consider the classifications which cover almost all the causes and forms of HRW behavior. Therefore, we can identify the HRW behaviors in this classification and select the corresponding ways in time.

\section{Causes}

All the staff is comprise the managers, professional technical personnel and operational employees depend on their different employment. In this section, we will analyze the reasons of different types' employees except the common factors such as the Force Majeure, family, diseases and so on.

\section{Managers}

Enterprise managers are composed mainly of senior and general managers. The reasons mainly have been focused on the improper ways on introducing or developing new members, the way to training and using them, and the inadequate salary incentive system. To senior, specifically, is mainly caused by the mismatch between the new members and the demand plan of organization's human resources, the differences of competency framework, the knowledge structure and the comprehensive quality. Moreover, the reward has become the symptom of their self-esteem and personal ability. They will leave automatically when the organizations don't retrain or reward them as their expectation. To the general management, realistically, the HRW behavior might be result in the wrong direction of training and using, and the uncertainty of the future promotion. Additional, general managers are still lives by the salary and welfare, and it seems more likely for them to leave for their support.

\section{Professional technical personnel}

In this article, the professional and technical personnel should be used only for those employees who own a high and above professional skills level. For professional technical personnel, the HRW could be a result of the mismatch of the professional and technical capacities, professionalism, moral quality and spirit of the coordinate, enterprise value and culture, the current salary, the job satisfaction to the organizations, poaching from competitors in the business and others to the organization. Moreover, they also prefer to choose those which can provide the more promising professional ideal and better salaries, working environment, development space to the original organization. Of course, the prevalent of recruitment platforms are other unimpeachable sources, which include the industry recruitment website, professional technique recruitment, personal recommendation, head-hunting service and others.

\section{Operational employees}

As the largest group of the organization, most of them do their best to fulfill the task which assigned by immediate superior because they always both have weak points on technique and management. The most important purpose of this group is to survive, so from the operational employee's perspective, the level of salary and welfare determines whether they could stay in the enterprise. Moreover, other factors such as the soft environment, training, promotion space, performance appraisal, and the career planning are also essential to it. Finally, some special employees are still existence under the protection of the New Labor Contract Law. That is to say, they shouldn't be fired even they don't fulfill their jobs by training ${ }^{[5]}$. So, to some content, the remained of the special employees can relatively run out others. In addition, it is also affected by the stage of the enterprise development. Organizations will take staff reduction for economic in order to alleviating burdens when the enterprise is on the verge of bankruptcy or in the difficult time. 


\section{Suitable HRW Ways to Different Types Employees}

Backup to the content of the HRW, we will try to draw a diagram to match the most suitable HRW ways to each type's employees (see Table1).

Table1: the Corresponding Table between Employees and the Suitable Ways

\begin{tabular}{|c|c|c|c|c|c|}
\hline \multicolumn{3}{|c|}{ Causes } & managers & $\begin{array}{c}\text { professional } \\
\text { technical } \\
\text { personnel }\end{array}$ & $\begin{array}{l}\text { operational } \\
\text { employees }\end{array}$ \\
\hline \multirow{4}{*}{\multicolumn{2}{|c|}{ Individual causes }} & resign & $\sqrt{ }$ & $\sqrt{ }$ & $\sqrt{ }$ \\
\hline & & voluntary turnover & $\sqrt{ }$ & $\sqrt{ }$ & $\sqrt{ }$ \\
\hline & & $\begin{array}{l}\text { duty dereliction } \\
\text { resignation }\end{array}$ & $\sqrt{ }$ & $\sqrt{ }$ & $\sqrt{ }$ \\
\hline & & $\begin{array}{c}\text { active incumbency } \\
\text { unemployment }\end{array}$ & & $\sqrt{ }$ & $\sqrt{ }$ \\
\hline \multirow{4}{*}{\multicolumn{2}{|c|}{ legal causes }} & $\begin{array}{c}\text { contract maturity } \\
\text { turnover }\end{array}$ & $\sqrt{ }$ & $\sqrt{ }$ & $\sqrt{ }$ \\
\hline & & retirement & $\sqrt{ }$ & $\sqrt{ }$ & $\sqrt{ }$ \\
\hline & & retirement for illness & $\sqrt{ }$ & $\sqrt{ }$ & $\sqrt{ }$ \\
\hline & & died & $\sqrt{ }$ & $\sqrt{ }$ & $\sqrt{ }$ \\
\hline \multirow{12}{*}{$\begin{array}{l}\text { organizational } \\
\text { needs causes }\end{array}$} & \multirow{3}{*}{ rigid } & staff reduction & & $\sqrt{ }$ & $\sqrt{ }$ \\
\hline & & dismissal & $\sqrt{ }$ & $\sqrt{ }$ & $\sqrt{ }$ \\
\hline & & lay off the last system & & & $\sqrt{ }$ \\
\hline & \multirow{9}{*}{ flexible } & rebuilding venture & & & $\sqrt{ }$ \\
\hline & & internal venturing & $\sqrt{ }$ & & $\sqrt{ }$ \\
\hline & & internal labor market & $\sqrt{ }$ & $\sqrt{ }$ & $\sqrt{ }$ \\
\hline & & suspension & & & $\sqrt{ }$ \\
\hline & & leaving training & & $\sqrt{ }$ & $\sqrt{ }$ \\
\hline & & early retirement & & & $\sqrt{ }$ \\
\hline & & flow in the post & & $\sqrt{ }$ & $\sqrt{ }$ \\
\hline & & $\begin{array}{c}\text { passive incumbency } \\
\text { unemployment }\end{array}$ & & & $\sqrt{ }$ \\
\hline & & human resources rent & & $\sqrt{ }$ & \\
\hline
\end{tabular}

Table 1 indicates that the organizations have a series of forms to deal with the HRW behaviors to each type's employees. Furthermore, the diagram makes it clear that the differences among the three types' employees about HRW behavior forms are mainly about the organizational needs, and they have a strong resemblance between the individual causes and the legal causes HRW behavior forms.

To mangers, the HR department can use the rigid ways and flexible ways such as the internal venturing and the internal labor market. Internal venturing is a stereotypical entrepreneurial model sponsored by employees who nursed an enormous aspiration. They can achieve their purpose by taking over organization's tasks or items actively under the support of the organization. To the mangers, it is a channel to release employment pressure by taking short-term projects and regional businesses. Internal labor market is a general name for a series of rules and procedures. It can guide various sorts of HRM work in a long-term employment conditions between employees and employers [6]. It can help the internal resources flows freely, and alleviate the current employment pressure for the managers.

To professional technical personnel, the HR department can use the rigid ways such as staff reduction and dismissal and the flexible ways such as internal labor market, training, suspension, and the human resources rent.

The operational employees almost suit all HRW forms expect the human resources rent. The thing to keep in mind is that we should fully consider the existence of the special employees when we adjust the employees' position in the organization.

\section{Construction of the HRW Mechanism}

In this section, let's review the former first. We must know the HRW is the long-term other than the short-term or subsidiary development strategy, and it has permeated all sessions of the HRM process. The standards, procedures and the support systems during the implementation process are the 
mechanism. In this section, we will point out the keys about what should be noted in a sound HRW mechanism. At present, the HRW mechanism in our country is still incredibly incomplete. The fact that our HRW is still driven by the policy and it also lacks sets of scientific and reasonable evaluation methods, assessment criteria and procedure. Furthermore, there are too many personal relations and interest exchanges in practice, which always result in dissatisfactions among the workers. Thus, we should construct the HRW mechanism focused on the different types of employees in time.

\section{Formulate Regulations According to the Provisions of the Law}

PRC Labor Contract Law (2013) should be considered the foremost law when the HR department formulates the regulations. The new Labor Contract Law has very strictly provisions in the rage of workers' rights. In this case, the organization should make detailed regulations as far as possible on the labor contract, and report the fruit to the local labor department to ensure the legitimacy. Moreover, the organization should document electronic records about employees' behaviors to avoid just in case.

\section{Popularize and Clear up the HRW ideas}

The organization should spell out the needs for HRW deliberately to staff especially the operational employees. It's easier for managers and professor technical personnel to accept it relatively. However, it's generally considered the embarrassing thing for operational employee result of the misunderstanding of HRW. The department must let them know being fired is not the thing they usually supposed to be, they are just the necessary results of the daily operation. The remnant workers can still search for work at the various media and talent market.

\section{Establishing the Long-term Mechanism and Taking Various Specific HRW Measures Depends on the Objects}

The HR department should feel out the situation first before we take any definite steps. Firstly, they should analyze the reasons and searches for the solving path referring to the table 1 . For example, to the managers, they should mainly focus on the voluntary turnover. Comparatively speaking, this situation is the foremost regret for organization for it can bring the most loss on the technology, capital, interpersonal relationship, art of leadership, ect. Likewise, they should analyze the other two types' employees in the same way. They can also use some highly individualized approach such as interview the turnover workers, investigate the job satisfaction, the informal discussion of brilliant directors, and install the employees' suggestion box (especially in the website), etc. Moreover, they should oppose the unreasonable regulations of the organization system which result in the HRW, and revise it.

Secondly, they should making performance appraisal indicators and setting "buffer zone". The purpose of "buffer zone" is to provide another opportunity to those who have a poor performance appraisal results or some other mistakes which might be forgiven once. In order to ensure the flexibility and humanization, we should take progressive measures as much as possible. For examples, we can adjust the professional technical personnel to the operational employees or retrain them temporary. Specifically, they can consider the alternative plan priority, such as freezing recruitment, stop reward, flexible job system, ect.

Thirdly, they should carry out the result strictly. The organization can urge the remnant workers leaving the primary position in certain period time. Before that, HR department should interview every single one of them for the last time. They can ask them what has puzzled them most, just like the unpleasant cooperation, the impressions about the organization, the noticed questions in future and so on. Department members should document it carefully to prevent the similar situation happening again.

Fourthly, they should assessment the entire procedure and update the necessary items. For example, they will check whether exist a clear and detailed planning scheme, a rigid implementation process, a pretty expect result, a harmonious work environment, a mutual pleasure dedication, and other factors in it. 


\section{Emphasize Cultivating the Auxiliary Measures}

Briefly, the auxiliary measures are to serve the questions left over by the HRW mechanism. The purpose is to ameliorate the enterprise image and ultimately improve the whole HRM level. There are three observations I'd like to share in this section.

Firstly, the organization should build a set of elastic compensation systems to give material and spiritual assistance to remnant workers. For example, they should establish a special fund for their allowance, retrain to update their skills, conduct intermediary organizations which own superb reputation and make most of the social security system especially the urbanite's minimum living security, unemployment insurance, basic living standards and reemployment of laid-off workers. In addition, they can provide complete psychological consultation service for psychotherapy. It is necessary to counsel them to relieve their mental pressures.

Secondly, the organization should set down the secrecy agreement and restraint of competition mechanism to protect organization from ulterior motives' workers. In particular, the department must enforce the core employees which including the senior executives, high-tech lever workers and others which have the responsibility to bear the mortgages of organizations trade secrets. Moreover, they shouldn't engage in the same or similar part-time job in same trade until they have leaven for a certain period of time.

Thirdly, we should establish the talent pool and take it into gradient arrays. In this way, we can ensure job vacancies can be filled in time and ultimately promote the normal operation of the organization.

\section{Conclusion and Future work}

In this paper, we analyzed the basic points of human resources withdraw, constructs the match model to try to search the inner mysteries among behaviors, causes and forms, and ultimately gives some suggestions to a sound human resources management mechanism.

However, this paper is only used the qualitative study on the research method for the limited of the subjective and objective conditions. Thus, we will try to put the research emphasis on the quantitative studies if we want to make any progress on this thorny issue. For instance, we can design the questionnaire and interview the objects, and make detailed statistical analysis through SPSS or MATLAB, which can explore the inherent laws of the human resources withdraw management. Furthermore, the HRW gives the organization or the employee a chance to affirm their values and their direction.

\section{Acknowledgement}

At the point of finishing this paper, I'd like to express my sincere thanks to all those who have lent me hands in the course of my writing this paper. First of all, I'd like to take this opportunity to show my sincere gratitude to my supervisor, Mr. Yuan, who has given me so much useful advices on my writing, and has tried her best to improve my paper. Secondly, I'd like to express my gratitude to my classmates who offered me references and information on time. Last but not the least, I' $d$ like to thank those leaders, teachers and working staff especially those in the School of Foreign Languages. Without their help, it would be much harder for me to finish my study and this paper.

\section{References}

[1] He Faping, Construction of Human Resources Withdraw Mechanism based on the Labor Contract Law Background. J. Journal of business activity, 2008(08): 54-55.

[2] Zheng Hong, the study of the downsizing in Insurance Company, Insurance Studies, 2008(12): 81-84.

[3] Yang Xiongdong. Research on Human Resources Withdraw Mechanismof GuangXi B College. Guangxi Universality, 2012. 
[4] Chen Xinmin, Cost-benefit analysis of employees dismissed. Economic Press of Guangdong. 2005.

[5] Pen Chunxiu, the Study of Human Resources Withdraw Mechanism. Seeker, 2005(06): 107-108.

[6] He Wangbing, Wang Huan. Construct the Human Resources Withdraw Bases on the New Labor Contract Law. Market Modernization Magazine, 2008(18): 316-317. 